\section{Utilização dos equipamentos de proteção individual por mototaxistas: percepção dos fatores de risco e associados}

\author{
Use of personal protective equipment for \\ motorcycle taxi drivers: perception of \\ risks and associated factors
}

Jules Ramon Brito Teixeira 1,2 Ninalva de Andrade Santos 3 Zenilda Nogueira Sales 3 Ramon Missias Moreira 1,3 Rita Narriman Silva de Oliveira Boery 1,3 Eduardo Nagib Boery 1,2,3 Ramon Araújo dos Santos 4 Tilson Nunes Mota 5

\footnotetext{
${ }_{1}$ Programa de Pós-graduação em Enfermagem e Saúde, Universidade Estadual do Sudoeste da Bahia, Jequié, Brasil.

2 Fundação de Amparo à Pesquisa do Estado da Bahia, Salvador, Brasil.

3 Departamento de Saúde, Universidade Estadual do Sudoeste da Bahia, Jequié, Brasil.

4 Hospital Calixto Midlej Filho, Itabuna, Brasil. 5 Secretaria Municipal de Saúde, Itabuna, Brasil.

Correspondência J. R. B. Teixeira Programa de Pós-graduação em Enfermagem e Saúde, Universidade Estadual do Sudoeste da Bahia. Rua Coronel Gondim 29, Ituaçu, $B A$

46640-000, Brasil. julesramon@gmail.com
}

\begin{abstract}
This study aimed to examine the practices and perceptions of motorcycle taxi drivers concerning the use of personal protective equipment (PPE), based on field research and an exploratory and descriptive qualitative approach. Thirty motorcycle taxi drivers from Jequie, Bahia State, Brazil, were interviewed. Data collection used a semistructured interview and questionnaire. Data were analyzed using thematic content analysis. The results showed: Category 1 - risk perception, subcategory conditioning/determinant factors for the use of PPE; Category 2 - adherence, subcategory adherence to the use of personal protective equipment; Category 3 - PPE as a protective factor against traffic accidents, subcategories 1 -work-related accidents, 2 - use of PPE at the time of the accident, 3 - non-use of PPE at the time of the accident. Finally, motorcycle taxi drivers clearly have some knowledge of personal protective equipment and even acknowledge the importance of its use, despite not always using it properly.
\end{abstract}

Protective Devices; Occupational Accidents; Traffic Accidents; Occupational Risks; Occupational Health

\section{Resumo}

Este estudo objetivou analisar as práticas e percepções de mototaxistas a respeito do uso dos equipamentos de proteção individual (EPI) por meio de pesquisa de campo, exploratóriodescritiva, de abordagem qualitativa. Foram entrevistados trinta mototaxistas do Município de Jequié, Bahia, Brasil. Para a coleta dos dados, foi utilizada a entrevista semiestruturada, e, como instrumento, o questionário. Os dados foram analisados pela Análise de Conteúdo Temático. Os resultados evidenciaram: Categoria 1 - percepção de risco, subcategoria - condicionantes/ determinantes para o uso do EPI; Categoria 2 adesão, subcategoria - adesão ao uso do equipamento de proteção ocupacional; Categoria 3 -o uso do EPI como fator de proteção em acidentes no trânsito, subcategorias 1 - acidentes ocupacionais, 2 - uso do EPI no momento do acidente, 3 - não uso do EPI no momento do acidente. Por fim, tornou-se explícito que os mototaxistas têm algum conhecimento acerca dos equipamentos de proteção ocupacional e, inclusive, atribuem importância ao devido uso desses instrumentos, entretanto, nem sempre fazem o uso adequado deles.

Equipamentos de Proteção; Acidentes de Trabalho; Acidentes de Trânsito; Riscos Ocupacionais; Sáude do Trabalhador 


\section{Introdução}

Estudo sobre as práticas e percepções dos mototaxistas concernentes ao uso dos equipamentos de proteção individual (EPI). Esses profissionais são atores sociais envolvidos na atividade do mototaxismo, um novo ramo dos transportes urbanos disponibilizado, em sua maioria, em bases informais e, muitas vezes, envolvido em acidentes de trânsito.

Segundo o Código de Trânsito Brasileiro (CTB), os principais equipamentos de segurança obrigatórios aos motociclistas são: capacete de segurança (com viseira ou óculos), calçado fechado e roupa adequada (jaqueta de couro, macacão, calça comprida), retrovisores, faixas refletivas, sinalizadores laterais, alça lateral, revestimento para o cano da descarga e mata-cachorro (equipamento utilizado na parte inferior da motocicleta que evita o contato do piloto ou passageiro com o motor) 1.

Em se tratando de motociclistas, em especial os mototaxistas, a não utilização dos EPI pode provocar muitos danos à saúde deles, bem como a toda a comunidade envolvida direta ou indiretamente com esse fenômeno. As consequências advindas dos acidentes de trânsito em decorrência do não uso ou uso inadequado desses equipamentos são cada vez mais frequentes, provocando diversos tipos de lesões, inclusive, levando ao óbito.

O estudo tem como objetivo analisar as práticas e percepções de mototaxistas a respeito do uso dos equipamentos de segurança ocupacional.

\section{Método}

Estudo descritivo, exploratório, qualitativo, realizado com trinta mototaxistas do Município de Jequié, Bahia, Brasil, escolhidos de maneira aleatória. A coleta foi realizada no ano de 2007, após aprovação do Comitê de Ética em Pesquisa da Universidade Estadual do Sudoeste da Bahia, sob protocolo no 063/2006, em pontos de mototáxi previamente identificados, por meio de entrevista semiestruturada, tendo, como instrumento, um questionário sociodemográfico e questões relacionadas ao uso do EPI. Os dados foram analisados pela técnica de análise de conteúdo temático categorial 2.

\section{Resultados}

Dos 30 mototaxistas participantes, prevaleceu o sexo masculino (80\%); a maioria na faixa etária dos 18 a 30 anos (70\%); solteira (56,7\%); não concluiu o Ensino Médio (40\%); e sobrevive com uma renda mensal de 1 a 2 salários mínimos (46,7\%), a qual, segundo eles, advém exclusivamente do serviço de mototáxi, já descontados os gastos com a manutenção do equipamento necessário ao trabalho. Destaca-se que $10 \%$ dos mototaxistas entrevistados são menores de idade, o que significa que não possuem habilitação para conduzir. As categorias e subcategorias empíricas que emergiram do corpus de análise estão dispostas na Tabela 1.

\section{Discussão}

Vários fatores estão associados como condicionantes e determinantes para o uso do EPI, os quais tratam da importância atribuída pelos mototaxistas ao uso dos EPI, da insuficiência econômica para aquisição dos equipamentos, dos aspectos estéticos, do incômodo quando os utilizam, da obrigatoriedade prevista pelo CTB, e, por fim, do desconhecimento dos equipamentos.

Sobre a importância atribuída pelos mototaxistas ao uso dos EPI, a maioria dos participantes acha importante e primordial para minimizar ou evitar as lesões decorrentes dos acidentes de trânsito e por ser obrigatório segundo o CTB 1 .

Contudo, de acordo com as unidades de registro da Tabela 1, alguns consideraram importante o uso dos EPI, entretanto, alegam não deter recursos suficientes para adquiri-los e, dessa forma, se protegem de outras maneiras durante a jornada de trabalho.

Alguns não acham importante o uso dos EPI, o que demonstra o descuido desses profissionais com a sua própria segurança ocupacional, com sua própria vida, bem como a de todos os atores sociais envolvidos no fenômeno do mototaxismo.

Por conseguinte, defendem que, apesar de não fazerem uso, eles estão pilotando dentro do previsto no CTB, obedecendo à sinalização, aos limites de velocidade, às ultrapassagens, dentre outros fatores. Todavia, como está previsto no $\mathrm{CTB}$, as exigências devem ser cumpridas na sua totalidade, não bastando, por exemplo, o simples uso do capacete como instrumento de proteção afinal, sabe-se que esse EPI protege apenas contra fatores determinantes de lesões decorrentes de impactos na cabeça 1 .

Ademais, apesar de acharem importante o uso dos EPI, alguns não os utilizam por acharem incômodo ou pelo aspecto estético. Dentre aqueles que não acham importante o uso dos EPI, alguns afirmam que os utilizam pela obrigatoriedade do CTB, para evitar multas e possível suspensão. 
Tabela 1

Categorias e subcategorias empíricas que emergiram dos conteúdos manifestos pelos mototaxistas.

\begin{tabular}{lll}
\hline Categorias Subcategorias Unidades de análise \\
\hline
\end{tabular}

Percepção de risco

Adesão

O uso do EPI como fator de proteção em acidentes no trânsito
Adesão e não adesão ao uso do EPI

Acidentes ocupacionais

Não uso do EPI no momento do acidente
"Eu acho muito importante usar os equipamentos porque evita que quebra alguma parte do corpo ou machuca quando tem acidente" (25) "[...] Eu acho importante usar os equipamentos, mas não tenho dinheiro para comprar" (5) "[...] Eu uso porque é muito importante, mas só tenho capacete e mesmo assim porque é emprestado" (5) "[...] Sei lá, fico com uma agonia quando uso aquela jaqueta porque Jequié é muito quente, ela é muito feia" (2) "O calçado mesmo eu nem uso porque aperta meu pé, dá chulé, e eu fico agoniado [...] Sabe? Eu tenho e deixo em casa, já fui até pego esses dias pela polícia, mas fazer o quê, me incomoda" (2) "[...] Eu nem uso porque me incomoda, quando a polícia me pega, eu ligo pra um amigo meu que é chefão lá, e ele libera minha moto e tira a multa" (2) "[...] eu só uso porque é obrigatório" (14) "[...] Dizem que, se não usar, a polícia pega na rua e prende a moto, só por isso mesmo que eu uso" (3) "[...] Ah sim, eu uso porque ta lá no Código que, se não usar, pode até perder a carteira, sabia?" (2) "[...] Eu acho importante e uso mesmo, além disso, protege meus clientes, né? E sabia que é obrigatório? Quem não usa pode perder a moto, e, de pontinho em pontinho, eu posso perder até a carteira de motorista" (3) "[...] Rapaz, se eu te falar a verdade eu não uso não, na verdade, eu nem sei o que é" (8) "[...] Eu desconheço" (3) "[...] Eu não sei o que é não, eu uso capacete e sapato, mas porque é a polícia que pede pra usar, senão é multado" (3)

"Eu gosto de usar os equipamentos que protegem a gente" (11) "[...] Eu uso capacete e bota" (5) "[...] Eu tenho e uso sempre" (5) "[...] Eu? Uso porque me protege" (21) "[...] Eu não usava mas vi muito acidente, e os caras ficaram tudo quebrado, por isso, eu uso pra mim proteger" (30) "[...] Às vezes, não tenho dinheiro pra comprar novo, mas, sempre que eu posso, eu compro e troco os meus porque sei que protege" (10) "[...] Rapá, é importante usar, e eu uso porque sei que estou fazendo o melhor pra mim, ou seja, estarei me precavendo das lesões se acontecer alguma coisa comigo e estarei também conquistando mais clientes, né?" (18) "[...] Eu uso pra não ser multado e pra me proteger também" (5) "[...] Eu não uso mesmo não [...] Eu não uso porque não tenho [...] Eu não uso e nem gosto de usar [...] Eu não uso porque incomoda" (20) "[...] Eu até que usaria se não deixasse a moto e eu tão feios [...] Eu não acho importante usar e não uso mesmo" (5) "[...] Eu não uso e, quando a polícia me pega, eu ligo pros meus amigos da própria polícia,

$$
\text { e eles me soltam" (18) }
$$

"Rapá, meu acidente foi feio [...] Já sofri acidente sim" (12) "[...] Eu bati num carro que vinha na frente e não prestei atenção, fiquei toda quebrada" (15) "[...] Minha sorte que eu tava de capacete, porque senão eu teria morrido porque bati num poste de frente" (2) "[...] Bateram em mim" (24) "[...] Bateram em mim, mas eu tava usando capacete" (14) "[...] Meu acidente foi feio, quase morri" (20) "[...] Eu bati em outro motoqueiro, mas eu tava errado, tava na contramão, mas dei sorte por causa do roupão e do capacete" (2) "[...] Foi terrível o acidente e piorou porque não tava usando equipamento nenhum de segurança, quase morri mesmo, tive traumatismo craniano e até em coma eu fiquei" (10) "[...] Minha sorte que eu tava usando o capacete, senão minha cabeça tinha tocado no chão" (9) "[...] Eu tava usando sim e num tive quase nada" (5) "[...] A sorte que minha moto tinha mata-cachorro" (5) "[...] Eu tive muita sorte porque tava usando luvas e a roupa toda, porque senão meu corpo teria se acabado no asfalto" (10) "[...] Eu estava usando e por isso me salvei" (12) "[...] Eu dou graças a Deus porque eu tinha retrovisor. Tinha um caminhão sem freio vindo atrás de mim, e consegui desviar, mas, mesmo assim, cheguei a bater" (9) "[...] Minha sorte que eu tinha comprado o capacete, a jaqueta e o sapato no dia, pra você ter uma ideia, não sobrou nada da minha moto, e eu escapei por pouco e por causa do equipamento" (13)

"Não estava usando" (30) "[...] Eu não estava usando não e me arranhei todinha, mas não me arrependo" (15) "[...] Não estava usando não e me arrependo por isso" (19) "[...] Eu quebrei o fêmur e tive traumatismo, se tivesse usando capacete, e a moto tivesse retrovisor, talvez, o acidente nem teria acontecido [...] Eu não usei e fiquei em coma, mas eu tinha em casa quase todos os equipamentos, só que não gosto de usar porque deixa minha moto feia" (8) "

[...] Eu não estava usando capacete e nem o cliente, ele não sobreviveu, mas eu dou graças a Deus" (10)

EPI: equipamento de proteção individual.

Nota: entre parênteses, está especificada a frequência de aparição das unidades temáticas de análise. 
O CTB, em seu art. 256, prevê que a autoridade de trânsito deverá aplicar, às infrações nele previstas, as seguintes penalidades: advertência por escrito, multa, suspensão do direito de dirigir, apreensão do veículo, cassação da Carteira Nacional de Habilitação, cassação da permissão para dirigir e frequência obrigatória em curso de reciclagem 1 .

A adesão ao uso do EPI está intimamente relacionada à percepção que os profissionais têm acerca dos riscos a que estão expostos e da susceptibilidade a esses riscos ${ }^{3}$. Alguns participantes fazem referência à adesão aos EPI, visto o caráter que eles têm de promover a sua segurança ocupacional. Além de estarem se protegendo, acreditam que, fazendo o devido uso dos equipamentos de proteção, terão a oportunidade de conquistar a confiança dos clientes e, assim, aumentar as possibilidades de trabalho e a garantia da satisfação da clientela. Porém, muitos profissionais banalizam os riscos ocupacionais com o desuso do EPI, não sabendo, na sua maioria, identificar as consequências decorrentes da inobservância do uso de medidas de prevenção ${ }^{3}$.

Os motociclistas, em geral, apresentam uma maior vulnerabilidade a acidentes de trânsito devido à exposição direta durante o impacto com outros veículos ou objeto fixo e, ademais, estão sujeitos a múltiplas e variadas lesões corporais 4 . Como exemplo, observou-se uma incidência anual de acidentes de trânsito de 10,5\% com mototaxistas regulamentados em Feira de Santana, Bahia, em 2011 4, e de 20,4\% com mototaxistas regulamentados em Fortaleza, Ceará, entre 2006 e 2007 5. Outros estudos realizados com mototaxistas constataram que a maioria dos profissionais já se envolveu em acidentes de trânsito 5 .

A ocorrência de acidentes de trabalho implica em danos sociais imediatos. Primeiro e mais importante, pelo comprometimento da saúde e integridade física do trabalhador. Segundo, pelos seus dependentes que podem, eventualmente, perder a base de sustentação familiar. Terceiro, pelos custos que ocorrem nas áreas sociais, principalmente na saúde 6 .

Nesse sentido, dentre os mototaxistas que sofreram acidentes durante a jornada de trabalho, várias foram as consequências advindas, as quais, de certa forma, levaram a uma ruptura no padrão de vida desses trabalhadores, reduzindo, consequentemente, o seu potencial de trabalho e de saúde. A prevenção dos acidentes é o meio mais importante para evitar a morbimortalidade pelas causas externas, e as ações concentradas em nível de prevenção primária poderão cortar a cadeia em seu momento inicial 7 .

Os mototaxistas revelaram que, muitas vezes, não foram os causadores dos acidentes, e que vários foram os danos corporais resultantes desses acidentes, os quais variaram de acordo com a utilização do EPI. Se, por um lado, as motocicletas oferecem vantagens econômicas e de mobilidade, por outro lado, a proteção do motociclista é precária. Eles informaram que apenas se salvaram ou tiveram as lesões corporais amenizadas por estarem usando algum tipo de EPI. Entretanto, apesar da importância desses equipamentos, ainda existem aqueles que apenas se conscientizaram após sofrerem acidentes e ficarem com sequelas, dos mais variados graus de gravidade, pelo não uso dos EPI 8 .

O capacete foi referenciado diversas vezes, configurando-se como uma possível representação dos EPI para os mototaxistas, pois é um equipamento indispensável para a sua segurança; diminui o risco e a gravidade de lesão na cabeça em cerca de $72 \%$; a probabilidade de morte em até $39 \%$ e os custos com o tratamento associado com colisão 9

No motociclista, exceto a cabeça protegida por capacete, o corpo fica vulnerável ao impacto, podendo ocorrer lesões múltiplas. As motocicletas não acompanharam as tecnologias para diminuir o impacto das colisões sobre os ocupantes. Por conseguinte, vários agravantes aumentam o risco para a ocorrência de lesões decorrentes dos acidentes de trânsito, tais como: comportamentos infratores dos motociclistas, dentre eles, a inobservância ao uso dos EPI; problemas climáticos e nas vias e a instabilidade própria desse veículo, facilitando derrapagens em curvas e nas conversões 10 .

Cabe ressaltar, ainda, que é indispensável a observação rigorosa da validade do equipamento para que esse ofereça a proteção necessária no momento do choque. Há de se destacar a importância da educação no trânsito, com adoção de comportamentos preventivos, e a implementação de medidas rigorosas de vigilância com a devida punição dos infratores 7 . 


\section{Resumen}

Este estudio tuvo como objetivo analizar las prácticas $y$ percepciones de mototaxistas sobre el uso de los equipos de protección individual (EPI). Estudio descriptivo, exploratorio, con enfoque cualitativo. Participaron 30 mototaxistas del municipio de Jequié, Bahía, Brasil. Para recoger los datos se utilizó como instrumento el cuestionario. Los datos fueron analizados mediante un análisis de contenido temático categorial. Los resultados mostraron que varios factores están asociados como los condicionantes y determinantes para el uso de EPI, tales como la importancia atribuida por los mototaxistas al uso de EPI, la insuficiencia económica para adquisición de los mismos, los aspectos estéticos y la incomodidad al utilizarlos, la obligación establecida por el Código Nacional de Tránsito y el desconocimiento de los equipos. Por último, se explicitó que los mototaxistas tienen algún conocimiento de los equipos de protección laboral e incluso atribuyen importancia a la debida utilización de estos instrumentos, sin embargo, no siempre hacen un uso correcto de ellos.

Equipos de Seguridad; Accidentes de Trabajo; Accidentes de Tránsito; Riesgos Laborales;

Salud Laboral

\section{Colaboradores}

J. R. B. Teixeira participou da elaboração do projeto, coleta, análise e interpretação dos dados, redação do artigo e revisão crítica relevante do conteúdo intelectual. N. A. Santos contribuiu na elaboração do projeto, análise e interpretação dos dados, redação do artigo e revisão crítica relevante do conteúdo intelectual. Z. N. Sales, R. M. Moreira, R. N. S. O. Boery, E. N. Boery, R. A. Santos e T. N. Mota colaboraram na análise e interpretação dos dados, redação do artigo e revisão crítica relevante do conteúdo intelectual.

\section{Referências}

1. Departamento Nacional de Trânsito. Código de Trânsito Brasileiro: Lei no 9.503, de 23 setembro de 1997. 3a Ed. Brasília: Departamento Nacional de Trânsito; 2008.

2. Bardin L. Análise de conteúdo. Lisboa: Edições 70; 2011.

3. Florêncio VB, Rodrigues CA, Pereira MS, Souza ACS. Adesão às precauções padrão entre os profissionais da equipe de resgate pré-hospitalar do Corpo de Bombeiros de Goiás, Brasil. Rev Eletrônica Enferm 2003; 5:43-8.
4. Amorim CR, Araújo EM, Araújo TM, Oliveira NF. Acidentes de trabalho com mototaxistas. Rev Bras Epidemiol 2012; 15:25-37.

5. Lira SVG. Comportamento preventivo e de risco no trânsito, referido por mototaxistas regulamentados em Fortaleza-CE [Dissertação de Mestrado]. Fortaleza: Universidade de Fortaleza; 2008.

6. Ministério da Previdência Social. Ocorrência de acidentes de trabalho conforme a GFIP. Informe de Previdência Social 2002; 14:1-12. 
7. Santos AMR, Moura MEB, Nunes BMVT, Leal CFS, Teles JBM. Perfil das vítimas de trauma por acidente de moto atendidas em um serviço público de emergência. Cad Saúde Pública 2008; 24:1927-38.

8. Neves F. Atributos da qualidade de capacete para motociclista: a percepção dos profissionais motofretistas e mototaxistas [Dissertação de Mestrado]. Santa Maria: Programa de Pós-graduação em Engenharia de Produção, Universidade Federal de Santa Maria; 2011.
9. Organização Pan-Americana da Saúde. Capacetes: manual de segurança no trânsito para os gestores e profissionais de saúde. Brasília: Organização PanAmericana da Saúde; 2007.

10. Marín-León L, Belon AP, Barros MBA, Almeida SDM, Restitutti MC. Tendência dos acidentes de trânsito em Campinas, São Paulo, Brasil: importância crescente dos motociclistas. Cad Saúde Pública 2012; 28:39-51.

Recebido em 02/Fev/2012

Versão final reapresentada em 05/Nov/2013

Aprovado em 08/Jan/2014 